\title{
Working Together: Librarian and Student Collaboration Through Active Learning in a Library Eclassroom
}

Marcie Lynne Jacklin

Liaison/Science Librarian

James A. Gibson Library, Brock University

Heather Pfaff

Collection Development Librarian

Region of Waterloo Library

\section{Keywords}

sociocultural factors; information literacy; active learning; constructivist; collaborative learning; bibliographic instruction

\section{Introduction}

Teaching information seeking skills to post-secondary students in a classroom setting can be a challenge. Often librarians are faced with a 50-minute session in which to instruct a large class of students on the library skills that they require to successfully complete their assignments. All too frequently, such lecture-based teaching fails because students do not pay attention, examples are overly simplified, or too much information is presented (Keyser 35). Feedback from students at Montana State University at Bozeman shows that students generally do not like traditional lecture-style bibliographic instruction (Ragains 41). Additionally, some theories propose that adults need to be able to use their own methods of learning and should be allowed to control the pace and nature of their learning (Rogers 71; Roy \& Novotny 138). Therefore, basing information literacy sessions for post-secondary students on active learning strategies, which directly involve students in the learning process (Bonwell \& Eison iii), should help to ensure that these learning experiences are appropriate and effective.

Active learning techniques can be informed by several learning theories, including constructivist theory, sociocultural theory and collaborative theory. Only a limited body of library literature describes the application of sociocultural learning theory to active learning in bibliographic instruction (Wang 151). This paper attempts to elucidate the role that sociocultural learning theory can play in bibliographic instruction by examining the use of active learning strategies during instruction sessions for second year Biological Sciences students at a mid-size Ontario university.

\section{Review of the Literature}

Current learning theories support engaging students in the learning process, and this is often referred to as "active learning". Active learning can be most simply described as "any teaching method that gets students actively involved" (Keyser 35). Bonwell and 
Eison define active learning as "instructional activities involving students in doing things and thinking about what they are doing" (iii), and they also describe some general characteristics commonly associated with active learning in the classroom:

- Students are involved in more than listening.

- Less emphasis is placed on transmitting information and more on developing students' skills.

- Students are involved in higher-order thinking (analysis, synthesis, evaluation).

- Students are engaged in activities (e.g., reading, discussing, and writing).

- Greater emphasis is placed on students' exploration of their own attitudes and values. (2)

The practice of active learning may be informed by various learning theories, including constructivist learning theory, sociocultural learning theory and collaborative learning theory.

Constructivist learning theory is derived from Vygotsky and classifies learning as a process whereby students interact with one another to construct meaning and build on prior knowledge together while completing authentic tasks (Good \& Brophy 408-415). In such a learning environment, the instructor's role is to intervene when necessary to help the students stay on track. (Cooperstein \& Kocevar-Weidinger 142). Cooperstein and Kocevar-Weidinger have noted that instructors should "'ask don't tell' and if [they] can structure the lesson to get students to ask the questions, so much the better" (142). This means that lessons should be structured so that students, as opposed to instructors, should ask and be asked as many questions as possible because this helps to facilitate students' independent discovery of concepts. However, Keyser (38) has noted that active learning can incorporate brief lectures to introduce topics/concepts because active/cooperative learning cannot completely substitute for explanatory lectures. Cognitive constructivist learning theories have been discussed and applied to information literacy teaching (e.g.Bordonaro \& Richardson, 2004), implemented in library computer classrooms (e.g., Smith, 2004; Zhang, 2007) and used to design online tutorials (e.g., Woodard, 2003). However, constructivist learning has been criticized for focusing too heavily on individual learning and ignoring the role that social and cultural contexts play in the learning process (Nuthall, qtd. in Wang 51).

Sociocultural learning theory, which is also based on the work of Vygotsky, takes a learner-centred approach (Wang 151) and focuses on the social construction of knowledge by communities of people (MacGregor 23). Jennings and Di (qtd. in Wang 151) assert that the social and cultural interaction on which sociocultural learning is based, make the context and content of the learning experience meaningful and, that without it, learning could not occur. Although sociocultural theory places greater emphasis on social and cultural context, the literature focusing on the application of this theory to information literacy activities is minimal. 
Collaborative learning theory is closely related to both constructivist theory and sociocultural theory (Smith 66; Wang 150). Collaborative learning emphasizes the social construction of knowledge and the importance of both teachers and learners taking an active role in the education process (Whipple 3 ). As in constructivist learning environments, collaborative learning environments require the instructor to act as a facilitator who shares authority with his/her students and helps learning take place (MacGregor 27).

The advantages of active learning are numerous. According to a summary of research presented by Allen (93), active learning helps to increase students' learning as well as their interest in learning, and it affects the cognitive, sensorimotor, and affective domains. Ridgeway (34-35) notes that active learning not only addresses the diverse learning styles of diverse students, but also helps to increase students' interaction with and retention of information, as well as their responsibility for their own learning. MacGregor (26) indicates that collaborative learning provides students the opportunity to stop looking to instructors and texts as the exclusive sources of authority and knowledge and to begin valuing themselves, their peers, and their groups as additional sources. Cooperstein and Kocevar-Weidinger have remarked that in social settings, "students are more relaxed, more likely to venture a guess, to share an opinion, to correct one another, to demonstrate confidence, and to feel less self-conscious about mistakes" (145). Collaborative learning also helps students learn from their mistakes (Smith 78) and improve their problem-solving abilities because they are exposed to a variety of perspectives on a given situation (Bruner, qtd in Gokhale 28). Gokhale asserts that "the active exchange of ideas within small groups not only increases interest among the participants, but also promotes critical thinking" (22).

In order to base instruction on sound learning theory, the active learning session described in this paper was based on elements of these three learning theories, with emphasis placed on the importance of community-based learning environments and the unique, yet interdependent, roles of the instructor and the learner. It can be seen that constructivist learning theory, sociocultural learning theory and collaborative learning theory are closely related and share many of the same principles. Therefore, elements of each can be seen in the methodology and results.

\section{Background}

Brock University has approximately 16,000 undergraduate students and 1,200 graduate students. The Biological Sciences class that was involved in this study typically has approximately 95 students enrolled. Students are divided into smaller groups for handson sessions, with each session having anywhere from 9 to 23 attendees. The students in this course are generally in their second year, however some third and fourth year students also take this course.

This instruction project involved the use of active learning techniques during a series of six workshops with approximately 16 students participating in each lab section. The senior librarian has been teaching a library lab for this course for the past six years. The 
lab was designed in collaboration with the Senior Lab Instructor for the course, and over the years it has evolved from a voluntary-attendance, lecture-style workshop to a mandatory-attendance lab in a hands-on e-classroom setting. This lab is now embedded in the curriculum and incorporates a course management system called Moodle. In the past, the lab was based in WebCT. The facilitators hoped that using Moodle would eliminate the technical problems that were experienced with WebCT.

Three facilitators led the labs: the Biological Sciences Librarian (i.e. the senior librarian), a second Liaison Librarian and a Master's co-op student. The Liaison Librarian had also participated in these labs the previous year during her co-op placement in the Library. The Biological Sciences Librarian attended all six sessions, and the Liaison Librarian and the Master's student attended three labs each.

\section{Methodology}

Students were presented with an online assignment based in Moodle that consisted of 19 questions in total (see Appendix A). The 14 multiple choice questions can be characterized as "treasure hunts" for answers, using clues provided. The remaining five questions on the assignment required students to complete tasks (e.g., importing citations into RefWorks - a bibliographic manager, creating a bibliography in RefWorks) and indicate their completion by filling in an answer box. It was possible to verify that students had, in fact, completed these tasks because the students emailed their completed bibliographies to the Biological Sciences Librarian. Moodle automatically marked the multiple choice answers and the Biological Sciences Librarian marked the bibliographies.

Students were given three hours to complete the assignment, and successful completion earned the students up to $2 \%$ of their final lab mark. Each student was provided with a computer, which was connected to the internet, on which he/she could complete the assignment. As it was not possible to book the same classroom for each session, the computer set-up varied from session to session, with some students working on desktop computers and others working on laptop computers that connected to the internet via wireless connection. In each classroom, however, the students' desks were arranged in rows. "Tips" on how to answer questions (e.g., links to informational web pages) were embedded within the assignment. Students were allowed to begin their assignment as soon as they arrived in the classroom. They were permitted to work at their own pace and with as many others as they wished. Students were also encouraged to ask questions by discussing the assignment with their peers and with the facilitators. Although discussion and collaborative group work were emphasized, each student was responsible for submitting his/her own assignment through Moodle.

The librarians began each session by providing an explanation of the assignment in order to orient the students to their task and to the resources available to them. Following this brief introduction, the facilitators left the lecture podium and engaged with the students in order to share their positions of authority. Periodically, throughout each instruction session, the facilitators delivered brief "standardized instruction topics" (i.e., 
brief lecture-style instruction, focused on teaching a particular skill/task) when it appeared that the class had common problems with a question. As a result of past experience with students' common questions, the Liaison Librarian had prepared a list of these topics ahead of time, so consistent instruction could be provided to all sessions. However, it was agreed that the facilitators would exercise a degree of flexibility in order to address the individual needs of the students in each session and would embrace the spontaneous "teachable moments" (i.e., "that moment when a unique, high interest situation arises that lends itself to discussion of a particular topic (Lozo par. 7)) that could arise from students' questions. The list of standardized instruction topics included: creating folders in RefWorks, importing citations into, and viewing them in, RefWorks, using Boolean operators, and accessing full-text in Google Scholar from off campus.

\section{Observations}

Several characteristics of active learning emerged. Groups of students were clearly engaged in discussion over the questions and answers, were asking each other questions, and were comparing and combining their perspectives to solve problems. Students tended to work mostly in pairs, within their rows. However, students were occasionally seen discussing with several of their peers in front of, or behind them. Students were heard making comments such as "Are we saying we need a password?" and "I'm just trying it". The answers for each assignment question were in random order which encouraged students to discuss the answers rather than simply saying "the answer is B". Some students who chose to work on their own seemed to ask more questions of the facilitators than the groups.

Each group of students reacted differently to the environment, and some classes asked more questions than others. In some sessions, the students did not ask as many questions as the facilitators hoped they would. Some students worked on their own, while others worked in groups of two, three or four. The organization of the work tables did not allow for overly large groups, which was likely beneficial to student learning as it allowed all students in each group to make contributions and to hear the contributions of peers.

Most problems encountered by the Biological Science students seemed to be related to the functionality of the tools they were asked to use (e.g., difficulty copying/pasting an RSS feed URL into RefWorks), rather than to research skills (e.g., creating search strings). Additionally, some students seemed to experience initial difficulty when they were asked to analyze a tool or resource in order to answer a question on the assignment. By engaging in discussion with the students, the facilitators were able to encourage them to analyze the software instead of searching for a clear-cut answer. Taking this active role in the learning process allowed facilitators not only to encourage critical thinking in the students, but also to learn from the students and to assist them in staying on track. 
The facilitators observed students' behaviour and apparent difficulties and taught topics based on these observations. Additional teaching topics were added to the original "standard list" based on these observations. An interesting observation that was made during the short instruction sessions and "teachable moments" was that the students did not appear to be listening; most of the students carried on working, especially during instruction on RefWorks. However, the resulting reduction in the number of questions pertaining to the instructed topics suggested that students had, in fact, benefited from them. Also, $66 \%$ of the students who commented on the evaluation forms mentioned how beneficial the RefWorks instruction was.

The facilitators worked well as a team. The senior librarian occasionally experienced a feeling of loss of control, due to the fact that she was sharing instruction responsibilities with others and giving up control of the classroom. However, she addressed this challenge by leaving the e-classroom whenever she felt the need to interrupt the other facilitator. This tactic helped the senior librarian to effectively share her authority with the other instructor and with the students (a requirement of active learning). Answering questions posed by the students and troubleshooting technical problems proved to be very demanding despite an average ratio of 8:1 students to facilitators.

\section{Results}

Through these instruction sessions, the key features of active learning were discovered: both facilitators and students took an active role in the educational process; the hierarchical relationship between facilitator and student was flattened as evidenced by the comfort level of the students in asking questions; collaboration created a community of learners (e.g., in many sessions the conversations were ongoing and animated); knowledge was located in the community rather than in the individual (e.g., the instructors observed that students who may not have joined a group were eavesdropping on other groups); knowledge was created, not transferred, as students built on prior knowledge (i.e., instruction and guides were minimal, so the students often had to draw on their existing knowledge to perform a new activity to find the correct answer) and the facilitators and learners each played unique, yet interdependent roles. The facilitators learned that it is important not to underestimate what is really happening in a collaborative environment (e.g., sometimes it appeared that students were not paying attention, but they were). The facilitators agree that this taught them something important about the exchange of information among students, in that all the ways in which they share information may not be directly observable.

By the end of the six sessions, standardized instruction topics had been expanded to include such topics as creating a RefWorks account and searching the Brock catalogue from within RefWorks. As the week progressed, the facilitators were able to become increasingly proactive with instruction topics because their observations from previous sessions highlighted topics that would likely need to be addressed in front of the whole class. This is evidence of the facilitators' active participation in the learning process and, as Whipple (3) notes, this type of participation on the part of facilitators is characteristic of collaborative learning. 
Many students expressed their appreciation for the opportunity to learn new skills either verbally or on informal evaluation forms. For example, in reference to learning about accessing full text via Google Scholar from off campus, one student commented "Awesome -- that's good to know!"

At the end of the lab, students were asked to fill out an evaluation form to provide feedback to the instructors. The evaluation form is presented in Appendix $\mathrm{B}$. The return rate on the evaluation was high -- 68 out of 94 students (72\%) who attended the labs filled in an evaluation and submitted it with an ethics approval form. When asked to indicate what they liked most about the library lab, $64 \%$ of the respondents reported that they liked "RefWorks". Some of the students mentioned that they liked everything about the workshop and a few commented on the helpful facilitators. One student commented that it helped with research processes that he and his friends had been struggling with in second year. Several expressed disappointment that they were not taught this information in first or second year. Several mentioned that the workshop was like "playing" and that they enjoyed searching for information. Several students commented that it was beneficial to go through the process of searching.

The following figures summarize additional data gathered from the evaluation forms. This data provided some interesting insights for the librarians.

The first section of the evaluation form asked students to rate the degree (strongly agree, agree, neutral, disagree, strongly disagree) to which they agreed with five statements:

- The main goals of this session were clearly stated by the library instructor

- The material presented in the session was new to me

- The information I learned in this session will help me look for information

- The amount of material covered was suited to the time allotted

- I felt comfortable asking questions when I needed help

The percentage of students who indicated that they "agree" or "strongly agree" with these statements is presented in Figure 1. 


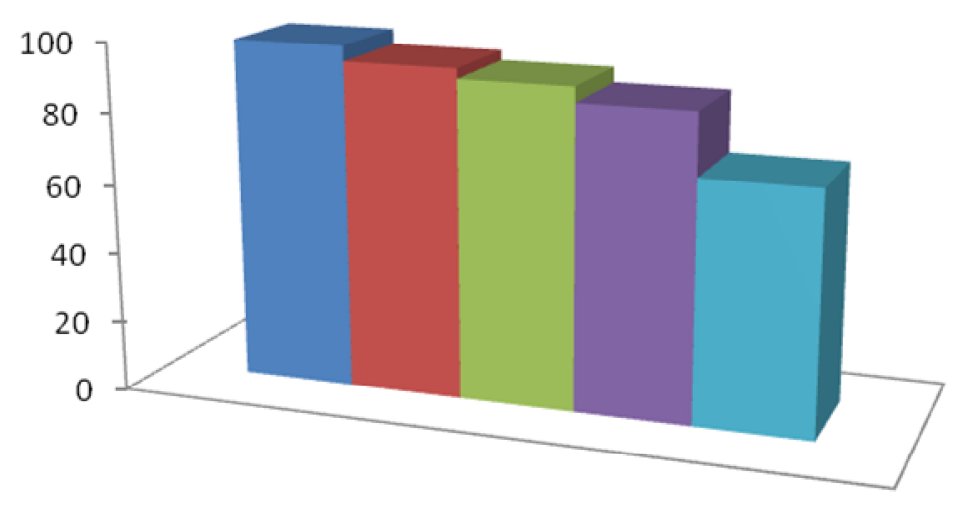

- Comfortable asking questions

n Amount of material covered was suited to the time alloted

Main goals were clearly stated

-What I learned will help me look for information

- Material was new to me

Figure 1: Percentage of students who agreed or strongly agreed with statements regarding the method of instruction.

In regards to the statement "The material presented in this session was new to me" the lower level of agreement (69.1\%) is suspected to be due to fact that a number of third and fourth year students were enrolled in this second year lab. A similar lab is also offered in another second year class and in a third year class, resulting in some overlap of content. It was satisfying to see that students were generally comfortable with asking questions (98.5\%). This suggests that the instructors' approach to instruction was successful in encouraging students to ask questions.

The next section of the evaluation consisted of three closed-ended questions which asked students about their impressions of the content of the session and their group work behaviour and preferences:

- The level of instruction was (too difficult; about right; too elementary)

- I worked mostly (with other students; on my own)

- I usually prefer to work (on my own; with one other person; in a group) Ninety-four percent of students indicated that the level of instruction was "just right". This was very satisfying for the librarians as it indicated that the questions they designed met the students' needs and abilities.

Figure 2 compares students' group work preferences with their actual group work behaviour in the library lab. It is interesting to note that while $38.6 \%$ of the respondents claimed to have worked on their own during the lab, the experience of the facilitators would have estimated this statistic to be approximately $10 \%$. These results also show that more students worked on their own (38.2\%) than the number who indicated that they preferred to work this way $(29.9 \%)$, suggesting that some students might have felt 
excluded from working with their peers. This may have been due to the linear arrangement of the classroom furniture which could have inhibited the formation of groups. In future years, the facilitators would like to change the wording of the question on the evaluation form to include an option for students to indicate whether they worked with just one other person or in a group, in order to refine the information gathered about how the students actually worked in the labs. In general, the librarians consider these results to be an indication of their success in creating a social learning environment. However, one might also question whether this environment coaxed students into working in a manner with which they were not comfortable.

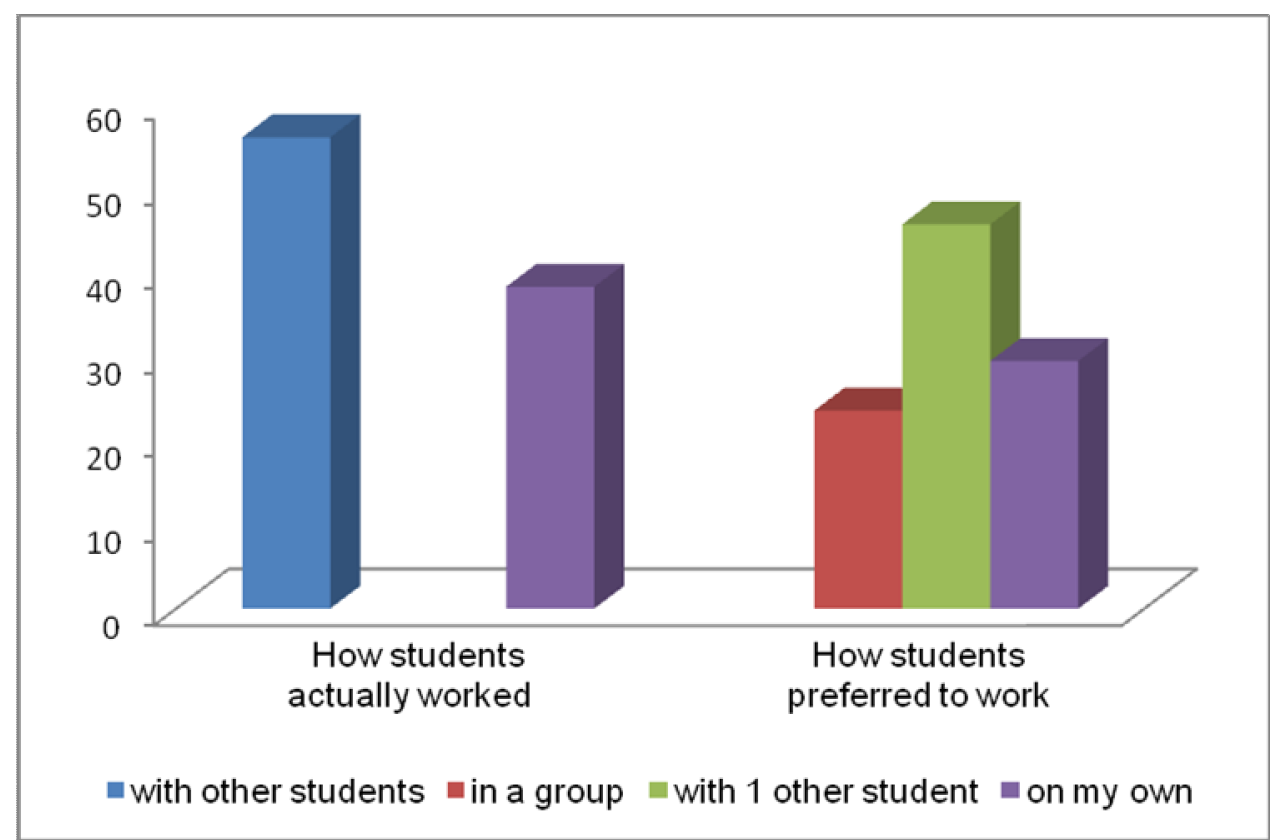

Figure 2: Students' reporting on how they worked in the session and their work preferences

The final two questions were opened-ended and were designed to obtain students' affective reactions and general feedback on the lab. The questions provided a variety of responses of which the most numerous are summarized (see Figures 3 and 4). 


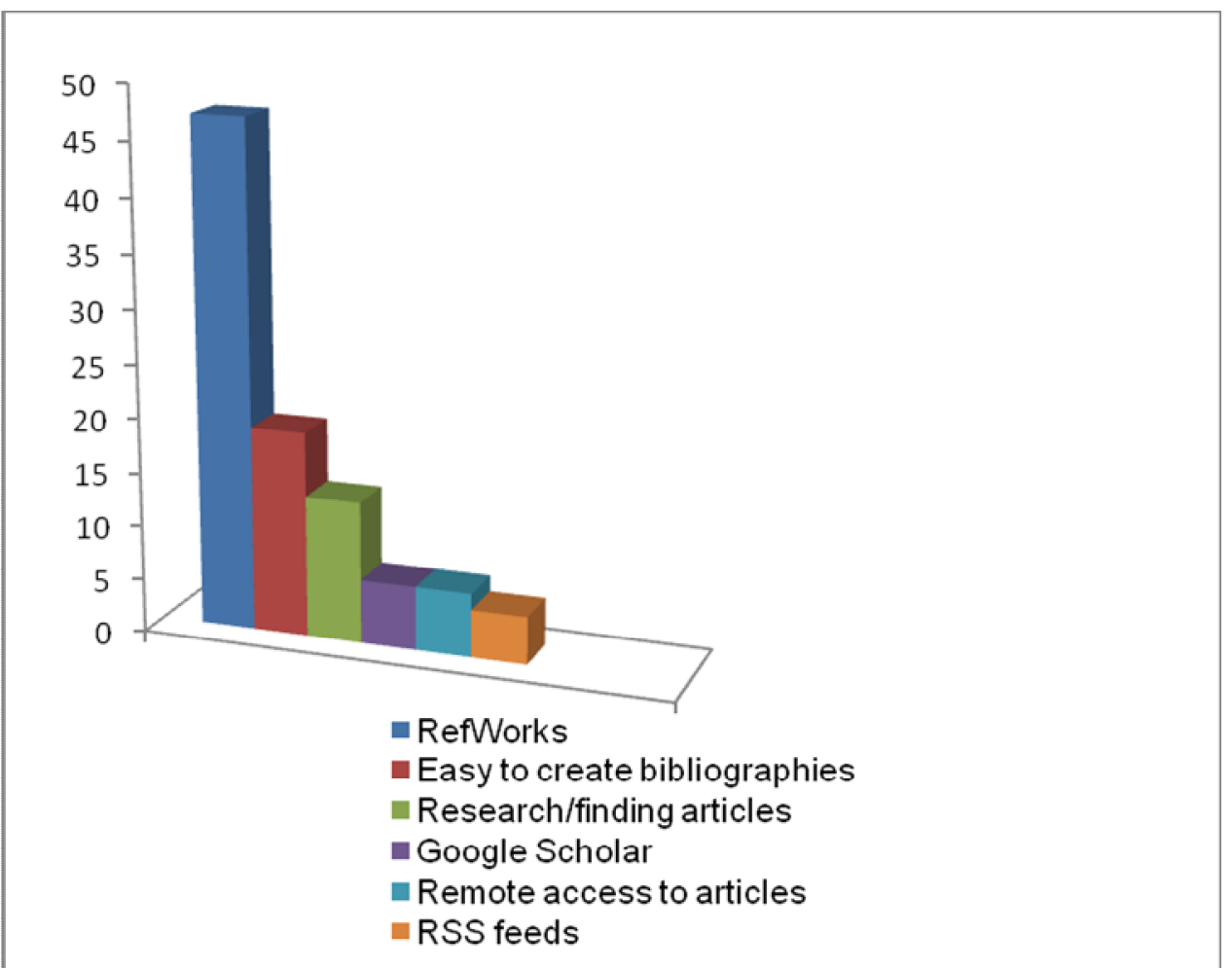

Figure 3: Students' reporting on what they found to be the most useful in the session

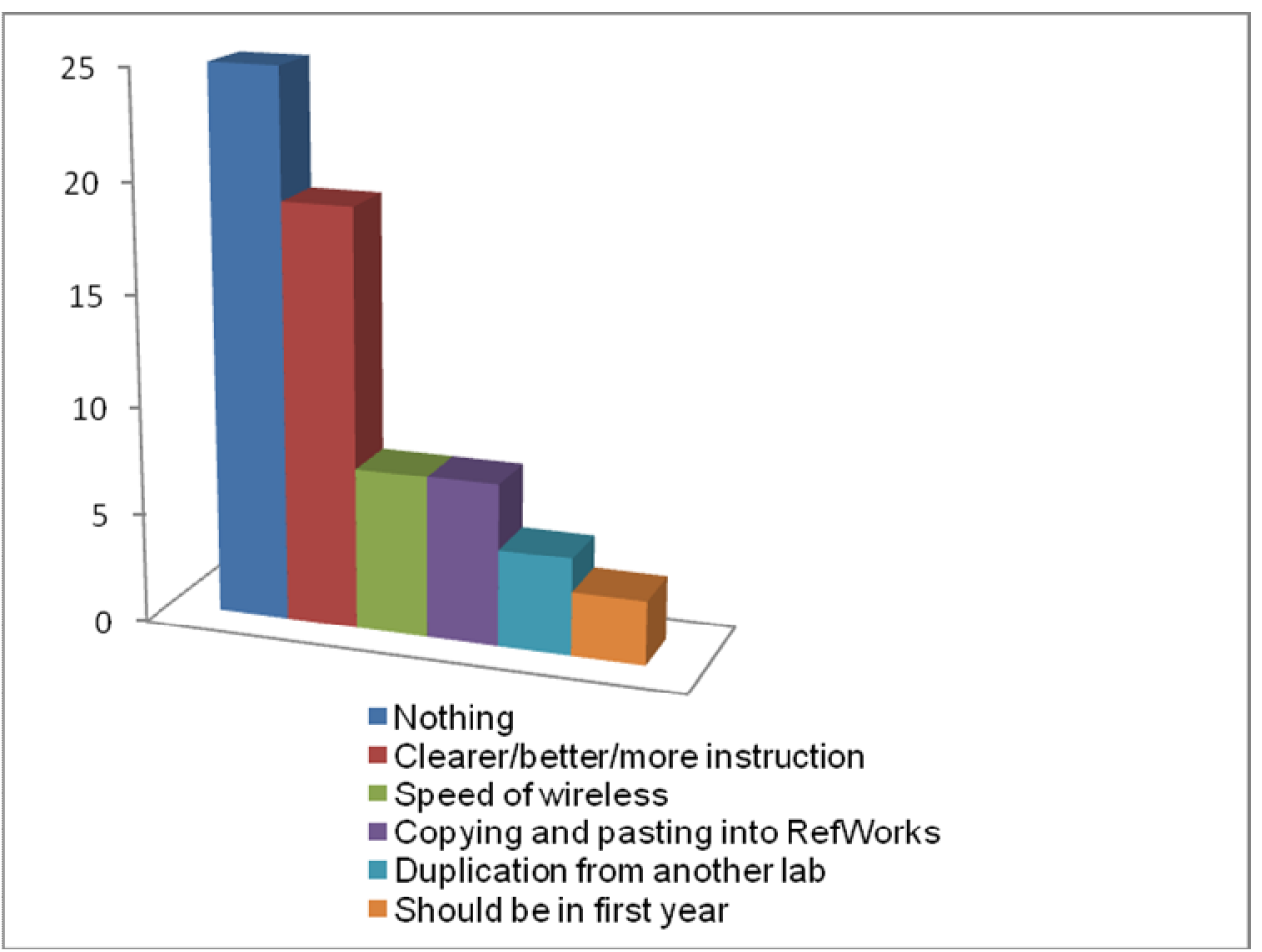

Figure 4: Students' responses to the question: "If you could change one thing to make this session better for you, what would it be?" 
A relatively large number of students indicated that they wanted clearer/better/more instruction. However the lack of instruction was done deliberately in some cases to generate problem solving discussion among the students. The problems copying and pasting were a result of an error in the set-up of the course management software. This technical issue we will be resolved for the 2010 series of labs.

The class average was $80 \%$ for this workshop and was worth $2 \%$ of the final grade. The goal next year will be to increase the average mark to $85-90 \%$.

\section{Discussion}

As evidenced above in the observations and results, the students seemed to both enjoy and benefit from the session. Additionally, many advantages associated with active learning were realized: students' interest in learning information literacy skills was increased; different learning styles were addressed by presenting information both visually, orally and through hands-on activities; and students interacted with the information given to them as well as with their peers. Therefore, it appears that many students came to value not only the facilitators, but also their peers as sources of knowledge, and they built new knowledge based on the perspectives of the group with which they were working. It is unclear as to whether students who worked alone were disadvantaged by this learning process, and it may be complicated to separate the effect of this component from the role that different learning styles play in learning outcomes. Such an investigation could be a topic for further investigation.

Although active learning provides many advantages for students, it does have associated disadvantages. These disadvantages can generally be characterized as barriers that instructors might face while attempting to implement lessons based on these strategies. According to Bonwell \& Eison, these barriers include:

- Difficulty in adequately covering assigned content in the limited class time available;

- A possible increase in the amount of preparation time;

- The difficulty of using active learning in large classes;

- A lack of needed materials, equipment, or resources. (v)

During the present instruction session, some expected disadvantages of active learning were experienced, yet several were avoided. No problems were experienced with adequately covering assigned content, and this was likely due to collaboration amongst the students and to the ample amount of time available to complete the assignment. Designing an active learning workshop is demanding and it was difficult to determine how long the students might need to complete the assignment. Developing appropriate questions for this type of instruction is time consuming; however the librarians will be doing some statistical analysis on the questions which will inform future changes to this assignment. 
Although there was a considerable amount of preparation time involved in designing the online assignment, the opportunity to work as a team during the design process certainly made the workload for each facilitator manageable, and the amount of preparation time was not considered to be a disadvantage by the librarians. In fact, the benefits of collaboration among the facilitators during both the planning and implementation phases of the session, was one of the greatest advantages experienced by the facilitators.

Resource barriers were a disadvantage, in that technological problems were encountered during each session. A glitch in the Moodle log-in system caused many students to have difficulty beginning the assignment. This resulted in frustration not only for the students, but also for the facilitators as there was no apparent cause of this glitch and it could not easily be fixed. Additionally, students in each session experienced problems with copying/pasting RSS links into RefWorks and copying/pasting a RefWorks bibliography into the answer box in the assignment. Therefore, moving the assignment to Moodle from WebCT simply changed the technical problems that were experienced, as opposed to avoiding them as the facilitators had hoped. The facilitators have concluded that it is quite difficult to deliver an electronic assignment without encountering some type of technical difficulty.

Additional disadvantages of active learning could include heightened instructor selfconsciousness, and instructors' fear of failure, criticism and loss of control/respect. Students may also refuse to participate, possibly due to the unfamiliar learning environment. Disadvantages for students could include heightened self-consciousness or the fear of potentially revealing weakness or ignorance to their peers (Allen, 95). The high percentage of students who reported on the evaluation that they would have liked clearer/better instruction may be indicative of students' resistance to active learning. It may seem contradictory to say that active learning has the potential to make students feel either more comfortable or more uncomfortable in an active learning classroom, however, it is important to remember that students not only have diverse learning styles, but also diverse personalities. Therefore, an instructional strategy that can make some students feel more comfortable could, in fact, make some students less comfortable. It is important to use balanced techniques so as to minimize disadvantages for as many students as possible.

The facilitators experienced neither fear of failure nor criticism either prior to or during the instruction session. The senior librarian did notice a feeling of loss of control. However, this stemmed from sharing instruction responsibilities with colleagues, rather than from using active learning techniques, and was easily remedied. Students' refusal to participate was generally not an issue during these instruction sessions, likely because of the degree of responsibility that was given to them for their own progress and learning. It was impossible to assess whether or not some students in groups were doing most of the work while others depended upon them for answers. Further research could investigate the degree to which social loafing (Latane, Williams \& Harkins 822) plays a role in collaborative learning groups. Latane, Williams and Harkins defined social loafing as "a decrease in individual effort due to the social presence of other 
persons."

Ragains has noted that "a confident, friendly demeanor" (41) is important for any guest speaker, so the facilitators needed to create a welcoming situation for the students so that they could embrace the positive aspects of a collaborative learning experience, and not only feel comfortable in the setting, but also feel free to comment and to ask questions. An additional role of facilitators in active learning settings is to help students stay on track with their tasks (Cooperstein \& Kocevar-Weidinger 142), and the practice of "checking in" with students not only helped with this, but also ensured that those who did not feel comfortable asking a question still received the facilitators' attention and had an opportunity to have their concerns addressed.

The facilitators did encourage question-asking, but perhaps they should have been even clearer about this from the beginning, because students' failure to ask questions could have been detrimental to their learning. It is difficult to determine whether the lack of questions was due to the social nature of the learning environment, the instruction from the facilitators, characteristics of the students (e.g., independence), a combination of these factors, or some other variable.

The instructors intervened with short, lecture-style instruction segments in two different ways. Since it had been noticed in previous years that students tended to have similar questions and difficulties, a set of standardized instruction topics was created in order to provide all students with a similar level of instruction. However, these instruction topics were generally presented to students only when the need for them arose. Additionally, the instructors took advantage of the "teachable moments" that arose from students' spontaneous questions by addressing common difficulties in front of the class.

Therefore, the groups that asked the most questions tended to receive the most overall instruction. Students who attended the first two labs achieved the poorest average grade on the assignment, and the highest average grade was achieved by the third lab session: the lab that initiated and received the most assistance from the facilitators! This supports Keyser's (38) assertion that traditional lecture-style teaching cannot be completely replaced with active learning strategies. It also underscores the importance of facilitator involvement in the learning process in an active learning classroom. Observations of students' difficulties in these instruction sessions will inform the development of additional standardized instruction topics for future instruction sessions.

An important consideration to keep in mind during active learning sessions is maintaining an appropriate balance of teachable moments and the encouragement of individual questions. In this study, "lecture style" instruction moments arose both from the instructors' list of standardized teaching topics (developed from prior experience) as well as from common questions from the students. A greater number of these "lecture style" teachable moments seemed to decrease students' questions, which suggests that they helped students tackle problems. However, as students' independent questionasking is vital for active learning, it must be ensured that instruction topics are delivered only when absolutely necessary so as to maintain students' motivation to ask questions independently. The combination of a hands-on activity, "tip sheet", and the 
encouragement of question asking is similar to Zhang's approach to instruction for Biochemistry students ("Promoting Critical Thinking, and Information Instruction in a Biochemistry Course," par. 9-11), and it helped to ensure that knowledge authority remained with the students and that they were able to remain as independent as possible.

Further research could shed more light on the benefits of active learning in libraries. For example, a more detailed and rigorous investigation of students' experiences and perspectives on active learning would make their affective experiences clearer. This paper relies on anecdotal observations which provide a starting point, but further insight into the true value of this type of learning, from the students' perspectives, could be gained if more structured data gathering techniques (i.e., interviews, formal feedback surveys) were employed.

A detailed analysis of students' assignment scores in relation to whether or not they worked in a group could help clarify the effect of group work on academic outcomes. This session was based on the facilitators' past teaching experiences in this Biological Sciences class; however, the assignment used in the past was significantly different from that used in the current session. Therefore, it is not appropriate to compare the effectiveness of the instructional methodology used in the current session with that used in the past. However, the success of the current session has motivated the instructors to continue with a similar assignment. Therefore, future research could clarify the degree to which using student feedback to inform the development of instruction affects the effectiveness of the teaching methodologies employed and ultimately, student learning outcomes.

\section{Conclusion}

It can be seen from this study that active learning can improve students' learning experiences as well as improve the professional experiences of librarians. Over the past six years, the senior librarian has increased the use of active learning techniques for this particular Biological Sciences class. For the current study, the size of the class and the series of repetitions allowed the facilitators to examine the students' reaction to this type of library instruction. The inclusion of additional facilitators as collaborators has both confirmed many of the senior librarian's observations from previous years and also revealed new aspects of the active learning experience (e.g., collaboration among multiple facilitators can help the advantages of active learning to outweigh the disadvantages). Based on feedback from students and from the Senior Lab Instructor the initial learning objectives, which were to increase students' information seeking skills in the Biological Sciences, have been realized. Therefore, this form of instruction will continue to be embedded into the curriculum for this course.

Incorporating active learning in hands-on instruction sessions enhances the students' learning experience and provides them with learning strategies that will benefit them beyond the classroom setting. Although challenging, and somewhat time consuming to create initially, subsequent sessions can simply be modified to fit the needs of a new 
class of students. A librarian considering this type of instruction may want to begin by devoting a portion of their allotted instruction time to active learning. The authors also highly recommend working collaboratively with colleagues if possible, as this significantly reduces the potential disadvantages of active learning. The advantages of this type of learning, for students and for instructors, (e.g., addressing diverse learning styles, increased student/librarian interaction, collaboration among instructions during the planning process) soon become the best motivation for preparing this type of session.

\section{Acknowledgements}

The authors wish to acknowledge Jacinta Dano for recognizing the need for information literacy instruction and allowing us into her lab sections; Heather Wellock for her assistance with designing, testing, and facilitating the delivery of the assignment, and Karen Bordonaro, Information Literacy Services/Instruction Coordinator Librarian, for her invaluable comments and edits on earlier drafts of this paper. 


\section{Works Cited}

Allen, Eileen E. "Active Learning and Teaching: Improving Postsecondary Library Instruction." Reference Librarian. 51 (1995): 89-103.

Bonwell, Charles C., and James A. Eison. Active Learning: Creating Excitement in the Classroom. Washington, DC: The George Washington University (ERIC Clearinghouse on Higher Education), 1991.

Bordonaro, K., and G. Richardson. "Scaffolding and Reflection in Course-Integrated Library Instruction." The Journal of Academic Librarianship 30.5 (2004): 391 401.

Cooperstein, Susan E., and Elizabeth Kocevar-Weidinger. "Beyond Active Learning: A Constructivist Approach to Learning." Reference Services Review 32.2 (2004): 1418.

Gokhale, Anuradha A. "Collaborative Learning Enhances Critical Thinking." Journal of Technology Education 7.1 (1995): 22-30.

Good, Thomas L. \& Jere E. Brophy. Looking in Classrooms. Boston: Allyn and Bacon, 2003.

Keyser, Marcia W. "Active Learning and Cooperative Learning: Understanding the Difference and Using Both Styles Effectively." Research Strategies 17.1 (2000): 3544. 
Latane, Bibb, Williams, Kipling and Stephen Harkins. "Many Hands Make Light the Work: The Courses and Consequences of Social Loafing." Journal of Personality and Social Psychology 37.6 (1979): 822-832.

Lozo, Fredric. Sequential Problem Solving: A Student Handbook with Checklists for Successful Critical Thinking. Project Gutenburg, 2005 http://www.gutenberg.org/files/16547/16547-h/16547-h.htm.

MacGregor, Jean. "Collaborative Learning: Shared Inquiry as a Process of Reform." New Directions for Teaching and Learning 42.Summer (1990): 19-30.

Ragains, Patrick. "Four Variations on Drueke's Active Learning Paradigm." Research Strategies 13.1 (1995): 40-50.

Ridgeway, T. "Integrating Active Learning Techniques into the One-Hour Bibliographic Instruction Lecture." Coping with Information Illiteracy : Bibliographic Instruction for the Information Age : Papers Presented at the Seventeenth National LOEX Library Instruction Conference Held in Ann Arbor, Michigan, 4 and 5 May 1989. Ed. Glenn E. Mensching, Jr. and Teresa B. Mensching. Ann Arbor: Pierian Press, 1989. 3334.

Rogers, Alan. Teaching Adults. 3rd ed. Buckingham, Philadelphia: Open University Press, 2002. 
Roy, Loriene, and Eric Novotny. "How do we Learn? Contributions of Learning Theory to Reference Service and Library Instruction." The Reference Librarian 69/70 (2000): 129-39.

Smith, Stefan A. "Designing Collaborative Learning Experiences for Library Computer Classrooms." College \&Undergraduate Libraries 11.2 (2004): 65-83.

Wang, Li. "Sociocultural Learning Theories and Information Literacy Teaching Activities in Higher Education." Reference \& User Services Quarterly 47.2 (2007): 149-58.

Whipple, William R. "Collaborative Learning: Recognizing it when we See it." AAHE Bulletin October (1987): 4-6.

Woodard, Beth S. "Technology and the Constructivist Learning Environment: Implications for Teaching Information Literacy Skills." Research Strategies 19.3-4 (2003): 181-92.

Zhang, Li. "Promoting Critical Thinking, and Information Instruction in a Biochemistry Course." Issues in Science and Technology Librarianship 51.Summer (2007): n. pag. Web. 14 May 2008. 


\section{Appendix $\boldsymbol{A}$}

\section{The following is a copy of the actual assignment completed by the students. Please note that links and attachments to various tip sheets, databases and other resources are not available.}

\section{Read this first!}

In this library lab, we are employing a method called "social learning" and you are encouraged to cooperate with your peers to complete the assignment. You are also encouraged to ask the instructors as many questions as you can - we are here to help!

This online module is a graded assignment that you will complete as part of the library lab. You may not know all the answers to the questions as they are designed to get you to think about, and explore, different resources.

This assignment will help you to learn more about:

- Peer-reviewed/scholarly articles

- RefWorks

- Searching Google Scholar

- Searching the library catalogue

- Searching library databases

\section{Some HINTS to start you off:}

1. You will be assigned an animal as your research topic. Make a note of this animal so you don't forget it

2. Use the HINTS and links provided in some questions for extra help

3. Some questions require more than one answer - read the HINTS carefully!

4. Sometimes you will be asked to both answer a question and move a citation into RefWorks - read all instructions carefully!

5. Remember to SAVE your answers often! To do this, scroll to the bottom of the assignment and click "Save without Submitting".

6. Ask as many questions as you can - ask each other and ask the instructors 9

\section{Library Lab Assignment}

This is a required assignment for your lab. You must complete the assignment during your lab time. You may attempt it as many times as you wish during this time, but you will not be able to access the assignment again once your lab session is over. 


\section{Grading method: Highest grade}

Question 1

Marks: 1

What criteria would you use to determine if a web page is a scholarly resource?

HINT: Use the CRAAP test to help you

Choose one answer.

a. The information is part of a peer-reviewed journal; the information is biased; no bibliography

[ $\mathrm{b}$. The author is named along with credentials; the article is aimed at the general public

c. The author is named along with credentials; the information is part of a peer-reviewed journal; there is a bibliography

a d. The information is current; the author works in a university and you can contact him/her there

Question 2

Marks: 1

A "scholarly" article is the same thing as a "peer-reviewed" article. But...what does "peerreviewed" mean?

HINT: Use this page to help you: http://www.library.brocku.ca/help/scpr.htm

Choose one answer.

a. The paper was reviewed by the journal editor(s) and accepted by the experts in the same field

b. The paper was reviewed by experts in the same field and accepted by the journal editor(s)

[ c. The whole class went to a bar and discussed the paper

c d. The author asked a colleague to look at his/her paper and check the spelling and

grammar

Question 3

Marks: 1

What does a scholarly (peer-reviewed) journal look like?

HINT: Use this page to help you again: http://www.library.brocku.ca/help/scpr.htm

Choose one answer.

C a. Contains ads; articles are less than three pages long

[ b. Contains pictures of people or places; articles are usually three or more pages long

c. The publication date or revision date is displayed; contains ads and pictures of people or

places

d. Articles are usually three or more pages long; they often have tables or charts or

diagrams; the publication date or revision date is available

Question 4

Which animal were you assigned in the library lab?

HINT: Type the singular form of your animal's name. That is, if your assigned animal is a "dog", type dog NOT dogs. 
Answer:

Question 5

Marks: 1

Create a RefWorks account by clicking HERE.

Within RefWorks, create a folder to use in the lab today (e.g., BIOL 2P92). RefWorks is a bibliographic manager which will be useful now, and in your third and fourth year courses. Take a few minutes to explore RefWorks. Which of the following can you do with RefWorks? HINT: There is more than one answer to this question! Choose all the answers that you think are correct.

HINT: RefWorks help can be found within RefWorks and by clicking here Choose at least one answer.

$\Gamma$ a. Automatically format your bibliography using one of many citation styles

$\ulcorner$ b. Search the catalogues at other university libraries

- c. Create a collection of citations that you have found in the library catalogue and in databases

$\Gamma$ d. Store full-text copies of documents that you find using databases

Question 6

Marks: 1

In RefWorks, use the search menu to look for books in Online Catalogues or Databases. Change the drop-down menu to "Brock University". Find a scholarly book related to your assigned animal topic. (HINT: You may not be able to find a book on your topic, in which case just find a book that is related to your topic).

If you wanted to find out where you could find your book in the library, what would be the fastest way to do it?

Choose one answer.

[ a. Look up the book's title or author in the library catalogue

[ $]$ b. Ask a library staff member using "LiveHelp"

[ C. Ask M arcie or Heather where to find it

[ d. Click on the "Get It" link in RefW orks

Question 7

Marks: 1

Choose one of the books that you found in Question 6 and move the citation for that book directly into your BIOL $2 \mathrm{P} 92$ folder. Which of the following pathways should you take to move your citation into this folder?

Choose one answer.

[ a a. Click "All in List" >Choose folder from drop-down menu >Click "Import"

[ $]$ b. Mark the desired citation >Choose folder from drop-down menu

[. c. Mark desired citation >Click "Import" >Click "View Last Imported Folder"

[ d. Mark desired citation > Click "Get It" >Click "GO"

Question 8 
Marks: 1

Now, try a search in the library catalogue: http://catalogue.library.brocku.ca/

This time, search for a resource that discusses your animal and a concept related to its form/function.

E.g., Animal $=$ bird, Form/function $=$ migratory behaviour

Here are some examples of form/function:

skeletons, symmetry, digestion, excretion, respirtaion, circulatory systems, lungs, environmental, any organ system, list at beginning of lab manual

Think of a search strategy that incorporates your animal and the form/function concept. You can use the examples below to help you.

Which example below would be the best to model your strategy after?

HINT: Click here to find out about using AND and OR in your search strategy

IMPORTANT NOTE: Once you find a resource you like, import the citation into your BIOL

2P92 folder.

Choose one answer.

[C a. "migratory birds" and behaviour

[C b. bird* and migrat* or behav*

[ C. bird* and migrat* and behav*

[C d. birds and "migratory behaviour"

Question 9

Construct a search strategy to find an article on your topic using Google Scholar. Move the citation into your BIOL 2P92 folder.

After you import the citation, take a look at it. Is the citation information complete? (type either yes or no)

Answer:

Question 10

Marks: 1

How can you access full-text articles through Google Scholar from off campus?

Choose one answer.

[C a. Go directly to http://scholar.google.ca and search just like you would on campus

[ b. Select "Google Scholar" from the library's alphabetical list of databases and log in

r c. This is a trick question. Most full-text articles in Google Scholar aren't accessible from off campus

c d. Go directly to http://scholar.google.ca, but make sure to obtain a password from the

L library first so that you can gain access to full-text articles without paying for them

Question 11

Marks: 1

From the library's group of databases for "Biological Sciences", select "Scholars Portal". Next, click on the green "advanced search" tab. Finally, change the "subject area" to "Natural Sciences" (drop-down menu). 
In 2003, Blake wrote a paper about ossicular homologies in echinodermata, which appeared in the Journal of Paleontology. Which of the following strategies would be best for finding the citation for this article?

Choose one answer.

a. BLAKE as author and JOURNAL OF PALEONTOLOGY as journal name and OSSICULAR

HOMOLOGIES as keyword

b. BLAKE as author and JOURNAL OF PALEONTOLOGY as journal name and "OSSICULAR

HOM OLOGIESIN ECHINODERM ATA" anywhere

C. BLAKE as author and JOURNAL OF PALEONTOLOGY as title and OSSICULAR HOM OLOGIES as keyword

d. BLAKE as author and JOURNAL OF PALEONTOLOGY as title and ECHINODERM ATA as

descriptor

Question 12

Marks: 1

Move the citation for the Blake article into your BIOL 2P92 folder. If you wanted to read this article, could you get a copy of it?

Choose one answer.

[] a. Yes, but only in print

[C. b. Yes, online or in print

[ c. Not at Brock, but I could order it through RACER

[C d. Yes, but only online

Question 13 뗘

Marks: 1

Why didn't searching for "OSSICULAR HOMOLOGIES IN ECHINODERMATA" work for finding the Blake article?

Choose one answer.

a. Because the spelling of ECHINODERM ATA shown in Question 12 is different from the

spelling of this word in the database

[ b. Because no article in the database contains all four of these words in any order

[C c. Because using quotation marks confused the database and caused the search to fail

a d. Because phrase-searching was used and these words don't appear as a phrase (i.e.,

together in the shown order) in any article in the databaase

Question 14

Marks: 1

For this question, continue to use the "Natural Sciences" grouping of Scholars Portal. In 2002, Brodman published an article about amphibians and reptiles in the journal American Midland Naturalist. Please find this article and add the citation to your BIOL 2P92 folder in RefWorks.

Which of the following strategies would be best for finding the citation for this article? Choose one answer.

[ a a. BRODM AN as author and AM PHIBIAN or REPTILE as title and 2002 as publication year

[ b. AM PHIBIAN* as keyword and REPTILE* as keyword and AM ERICAN M IDLAND 
NATURALIST as journal name

C. BRODM AN as author and AM ERICAN M IDLAND NATURALIST as journal name and 2002 as publication year

d. AM PHIBIAN* anywhere and AM ERICAN M IDLAND NATURALIST as journal name and 2002 as publication year

Question 15

Marks: 1

Look at the "DESCRIPTORS" on the right hand side of the citation that you found in Question 14.

What are descriptors?

Choose one answer.

C a. They're the same as keywords - just with a different name

b. Terms that describe what an article is about that can help me to find articles that are

relevant to my topic

L. c. An extra feature of the database that isn't really that important for doing a good search

C d. Words that appear many times in the full-text of the article

Question 16

Marks: 1

There is no such thing as a "perfect" search strategy. How can you know when you have done the best search possible?

Choose one answer.

[ a. All of the answers

C b. You have done more than one search and have collected and tried different keywords

[. c. You have used more than one database

d. You have more citations in your results than you require, so you can scan the list and pick out the articles that best meet your needs

Question 17

Marks: 1

You should now have five citations in your BIOL 2P92 folder.

Using the descriptors on the Brodman article, or keywords that you think of yourself, search for some more articles related to your topic.

Select at least five of the citations that you find and add them to your BIOL 2P92 folder. Next, view duplicates to make sure that all the citations in this folder are different. If you have duplicate citations, delete them and replace them with new citations. Your BIOL 2P92 folder should now contain at least 10 DIFFERENT CITATIONS.

Choose one answer.

C. a. I have checked for duplicates and my folder contains at least 10 different citations

C b. I don't mind losing a mark on this question

Question 18

Marks: 1

RSS (really simple syndication) can help you stay up to date with current news/research by sending you automatic updates. 
Go to the website for the Online Journal of Biological Sciences by following this link:

http://www.scipub.org/scipub/c4p.php?j_id=ojbs

Stay up to date with new articles published in this journal by creating an RSS feed that delivers new citations directly to your RefWorks account. Once you have added the RSS feed to RefWorks, choose one of the citations generated by the RSS feed and add it to your BIOL 2P92 folder.

Once you have completed this task, type done in the box.

HINT: Start by finding the orange RSS button on the web page. Right click on this button and choose "copy shortcut". Explore RefWorks and try to figure out how to add the RSS feed to your database. If you need help, just ask! 9

Answer:

Question 19

Marks: 4

Your BIOL 2P92 folder should now contain at least 11 citations: the 10 that you found by searching and 1 from your RSS feed.

Create a bibliography of the citations in your BIOL 2P92 folder. Choose a citation style like APA or CBE. Make sure to choose "Word for Windows (2000 or later)" as the file type.

Now copy and paste your bibliography into the box below. Once you are finished you can leave the library lab. If would like to help us improve this lab please read and complete the evaluation form.

Happy searching!

Marcie and Heather

Answer: 
Partnership: the Canadian Journal of Library and Information Practice and Research, vol. 5, no. 1 (2010)

\section{Appendix B}

\section{Library Instruction Session Evaluation \\ BIOL 2 P9 2 Library Lab .. March 2009}

Ple ase fill in this form in order to help the library instructor evaluate how successful this session was and de termine what improvements can be made. Your input is a critical part of this process and a thorough response will be very useful.

1. The results of this survey will be compiled and analysed for possible publication. Check this box if you consent to having your survey used in this manner? Forms submitted without this box checked will not be used for research purposes.

2. Indicate the degree to which you agree or disagree with each statement.

\begin{tabular}{|l|l|l|l|l|l|}
\hline Statement: & $\begin{array}{l}\text { Strongly } \\
\text { Agree }\end{array}$ & Agree & $\begin{array}{l}\text { Neutral/ } \\
\text { Undecided }\end{array}$ & Disagree & $\begin{array}{l}\text { Strongly } \\
\text { Disagree }\end{array}$ \\
\hline $\begin{array}{l}\text { The main goals of this session } \\
\text { were cle arly stated by the } \\
\text { library instructor. }\end{array}$ & & & & \\
\hline $\begin{array}{l}\text { The material presented in the } \\
\text { session was new to me. }\end{array}$ & & & & \\
\hline $\begin{array}{l}\text { The information I learned in } \\
\text { this session will felp me look } \\
\text { for information. }\end{array}$ & & & & \\
\hline $\begin{array}{l}\text { The amount of material } \\
\text { covered was suited to the time } \\
\text { allotted. }\end{array}$ & & & & \\
\hline $\begin{array}{l}\text { I felt comfortable asking } \\
\text { questions when I ne ded help }\end{array}$ & & & & \\
\hline
\end{tabular}

3. The level of instruction was:

\begin{tabular}{|l|l|l|}
\hline Too difficult & About right & Too elementary \\
\hline & & \\
\hline
\end{tabular}


4. I worked mostly:

\begin{tabular}{|l|l|}
\hline With other students & On my own \\
\hline & \\
\hline
\end{tabular}

5. I usually prefer to work:

\begin{tabular}{|l|l|l|}
\hline On my own & With one other person & In a group \\
\hline & & \\
\hline
\end{tabular}

6 What did you find the most useful in the session today?

7. If you could change one thing to make this session better for you, what would it be? 